\title{
Increasing Prevalence of Hypertension in Bangladesh: A review
}

\author{
Kamrun Nahar Koly ${ }^{1}$, Tuhin Biswas ${ }^{1}$, Anwar Islam ${ }^{1,2}$ \\ ${ }^{1}$ Center for Control of Chronic Diseases, International Center for Diarrhoeal Diseases Research, \\ Bangladesh (ICDDR,B), Dhaka, Bangladesh, ${ }^{2}$ School of Health Policy \& Management, Faculty of \\ Health, York University, Toronto, Canada
}

Key Words :

Hypertension;

Blood Pressure;

Prevalence;

Bangladesh.

\begin{abstract}
:
Hypertension is a major public health problem globally in both the developed and developing countries. In Bangladesh, approximately $20 \%$ of adult and $40-65 \%$ of elderly people suffer from hypertension. According to Non Communicable Disease risk factors survey, one third of the Bangladeshi population never measured their blood pressure. The prevalence of self reported hypertension was 12.5\% (men 10.9\% and women 13.9\%). Many risk factors underlying hypertension have been identified including non- modifiable factors such as age, gender, genetic factors, and race, as well as modifiable factors including overweight, high sodium intake, and reduced physical activity. The aim of this review was to present the scenery of hypertension and as well as present the exponential trend of hypertension in Bangladesh. We included 9 studies for the review that met the inclusion criteria and study objectives. Analyses of exponential trend reveled an increase in hypertension prevalence among adult population at a rate of $0.04(R=0.33)$ per year. This review studies have demonstrated that interventions aimed at changing these modifiable factors might contribute to prevent the development of hypertension.
\end{abstract}

(Cardiovasc. j. 2015; 8(1): 59-64)

\section{Introduction:}

A transition towards the globalization, market driven economics, environmental and life style factors are some of the major contributors in the epidemiological shifting that is predominantly characterized by Non Communicable diseases (NCDs) worldwide. ${ }^{1}$ Substantial global disease burden due to NCDs is causing an estimated death of 36 million in each year (60\% of total global death) which can be projected up to $17 \%$ by $2015 .^{2}$ And $80 \%$ of this death is occurring in low and middle income countries (LMIC). Likewise, in South East Asia region, 54\% of total death is resulting from NCDs. Bangladesh has come a long way combating some of the major communicable diseases causing existence of double burden of the diseases at the same time. However, though the current surveillance system is yet to be implemented appropriately, NCDs magnitude has been illustrated to be comparatively high in the country. Stroke/ heart disease, hypertension (HTN), diabetes, COPD and Cancer are some of the major NCDs and account for $68 \%$ death in Bangladesh. ${ }^{3,4}$ Among them HTN is an emerging epidemic and its prevalence was found to be within 15-20\% among the adult population of Bangladesh. It's the major modifiable risk factor for cardiovascular disease and some other complications like heart failure, renal failure etc. And all countries regardless of their economic status, addressing this burden as a major public health concern. This strategy includes understanding the to risk factors of the major NCDs as well. ${ }^{5}$ Hypertension has modifiable risk factors related to lifestyles, primarily tobacco smoking, lack of physical activity, unhealthy diet, harmful use of alcohol etc, are modifiable. ${ }^{6}$

Besides, number of the studies and representative data on the prevalence of HTN in Bangladesh is often inadequate and are not readily available. Moreover, estimates for adults are lacking in most of the studies. Many articles have been published in local, non indexed journals but they are not often

Address of Correspondence : Dr. Kamrun Nahar Koly, Center for Control of Chronic Disease (CCCD), International Center for Diarroheal Disease Research, Bangladesh (ICDDR,B), Dhaka, Bangladesh. Email: koly@icddrb.org 
available online and difficult to access. Therefore, taking such things in to account this study aims to reveal a clear understanding about the prevalence and risk factors of HTN in Bangladesh. This review might influence the policy makers for reviewing or changing existing policies.

\section{Methodology:}

The study is a synthesis of published studies that reflect overall prevalence and associated risk factors considering the biases and limitations of those studies. The procedure begins with literature review of all the published documents from the peer reviewed journals and online searches. The selection criteria would be, to only review the document understandable and standard diagnostic definition of HTN and conducted in the adult's age group. Literatures from 1971 to 2009 were included that discussed about prevalence and risk factors of HTN in Bangladesh. For documents retrieval different search engines like: Google Scholar, Pub Med, Bio Med central, Bangla Jol etc had been used. And the keywords were prevalence, risk factors, HTN, Bangladesh. Overall, 13 studies can be located. Two of the studies could not be accessed where 1 study was done in the school going children. The rest two was done in clinical settings and did not discuss the essential information. So, remaining 9 studies were included in this study for reviewing. ${ }^{7-15}$

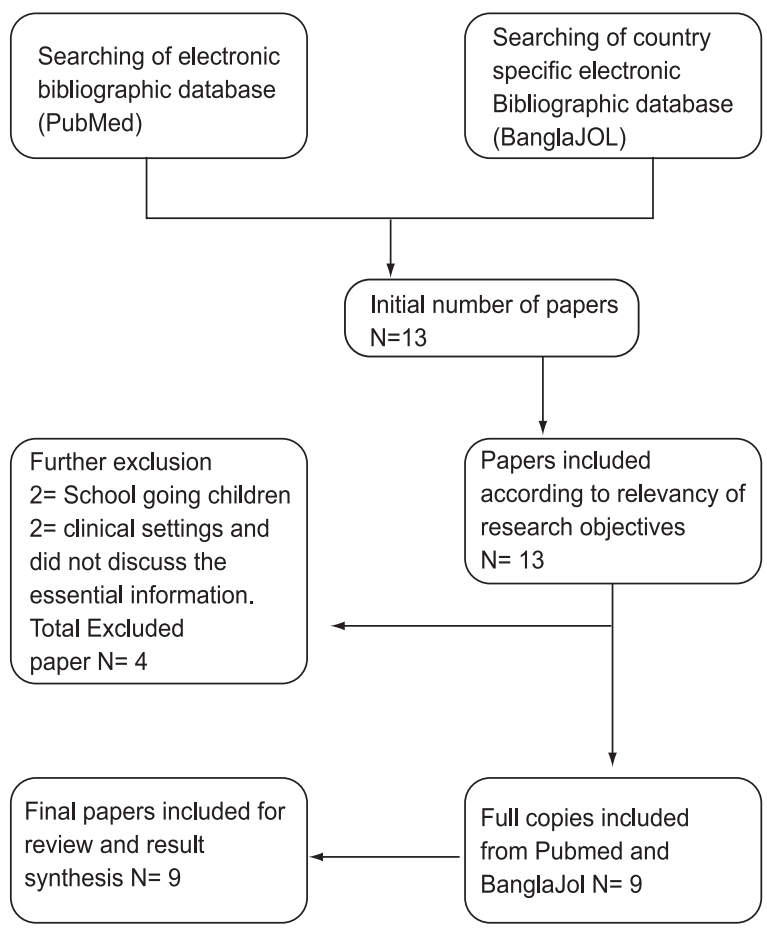

Fig.-1: Flow Chart for selection of studies.

\section{Result:}

\section{Study Settings:}

Considering the inclusion and exclusion criteria overall 9 studies have been included on prevalence of HTN in urban and rural areas of Bangladesh which is shown in Table I. After an extensive searching, literatures that have been retrieved were from the oldest period of 1971 to 2009 in recent. Almost all of the studies ( $\mathrm{n}=$

9) included participants from both sexes except for the one which was solely concerned with the females. Age range of the participants varied from above 15 years to around 65 and one study exclusively included the elderly participants. In terms of the study site, all of the studies were cross sectional. Fifty percent study was focused on urban, forty percent on rural and only ten percent study on both urban and rural area. All of the studies were primary research had been done on community settings, only one which was conducted at the outdoor of a medical college.

\section{Diagnostic criteria:}

Relatively all of the studies used seventh Report of the Joint National Committee on the Prevention, Detection, Evaluation, and Treatment of High Blood Pressure (JNC VII) criteria [systolic blood pressure (SBP) $<140 \mathrm{mmHg}$ and diastolic blood pressure $(\mathrm{DBP})>90 \mathrm{mmHg}$ ] their diagnostic standard for HTN cut off value except for two of the older studies. One of the study used SBP $>150$ $\mathrm{mmHg}$ as their HTN cut off value where as another used DBP>90 mmHg only. Overall prevalence of HTN in urban and rural area of Bangladesh may be varied due to different community settings, age variation etc

\section{Prevalence of hypertension:}

All of the 9 studies reported prevalence of HTN in Bangladesh and as a primary outcome among eight of them. Moreover, the prevalence of HTN varied and could not be contrasted across the studies because of the different diagnostic criteria, diverse age range and study settings. Nevertheless, the reported prevalence rate has been summarized according to the urban/rural settings and presented in table I. Using the old criteria (SBP : $>150 \mathrm{~mm}$ of hg and DBP >90 mm of hg) one of the oldest study (done on 1971-76) reported the prevalence of HTN was $2.58 \%$ within a mixed community of 
Table-I

Prevalence and risk factors of HTN in Bangladesh

\begin{tabular}{|c|c|c|c|c|c|c|}
\hline $\begin{array}{l}\text { Author name/ } \\
\text { publication year }\end{array}$ & $\begin{array}{l}\text { Sample } \\
\text { size }\end{array}$ & Method & Diagnostic Criteria & $\begin{array}{l}\text { Age } \\
\text { Group }\end{array}$ & Result & Risk factors \\
\hline \multicolumn{7}{|l|}{ Urban Community } \\
\hline Waliullah ,1971-76 & 16392 & $\begin{array}{l}\text { Cross sectional } \\
\text { survey }\end{array}$ & $\begin{array}{l}\text { Above 150/90 } \\
\mathrm{mm} \text { of hg }\end{array}$ & $>20$ years & $\begin{array}{l}2.58 \% \\
\text { Male- } 2.7 \% \\
\text { Female- } \\
2.36 \%\end{array}$ & N/A \\
\hline $\begin{array}{l}\text { Alamgir et al. } \\
2004\end{array}$ & 493 & $\begin{array}{l}\text { Cross-sectional } \\
\text { survey }\end{array}$ & $\begin{array}{l}\mathrm{SBP}=>140 \mathrm{~mm} \text { of } \mathrm{hg} \\
\mathrm{DBP}=>90 \mathrm{~mm} \text { of } \mathrm{hg}\end{array}$ & $18-64$ & $27.6 \%$ & $\begin{array}{l}\text { Body weight/BMI } \\
\text { Tobacco } \\
\text { Physical exercise }\end{array}$ \\
\hline $\begin{array}{l}\text { AKM Alamgir et al. } \\
2005\end{array}$ & 378 & $\begin{array}{l}\text { Cross-sectional } \\
\text { survey }\end{array}$ & JNC-7 criteria & $18-64$ & $\begin{array}{l}14 \% \\
\text { Stage I } \\
\text { HTN: } \\
\text { SBP- } 13 \% \\
\text { DBP-15\% }\end{array}$ & $\begin{array}{l}\text { Tobacco smoking, } \\
\text { extra salt intake, } \\
\text { family history }\end{array}$ \\
\hline $\begin{array}{l}\text { Ahmedul et al } \\
2007\end{array}$ & 17792 & $\begin{array}{l}\text { Cross-sectional } \\
\text { survey }\end{array}$ & $\begin{array}{l}\mathrm{SBP}=>140 \mathrm{~mm} \text { of } \mathrm{hg} \\
\mathrm{DBP}=>90 \mathrm{~mm} \text { of } \mathrm{hg}\end{array}$ & $13->55$ & $\begin{array}{l}3.11 \\
\text { Female=67. } \\
33 \% \\
\text { Male } \\
=32.67 \%\end{array}$ & Diabetes Mellitus \\
\hline \multicolumn{7}{|l|}{ Rural Community } \\
\hline $\mathrm{N}$ islam et al, June 1983 & 5026 & $\begin{array}{l}\text { Cross-sectional } \\
\text { survey }\end{array}$ & $\begin{array}{l}\text { Diastolic Bp above } 90 \\
\mathrm{~mm} \text { of hg }\end{array}$ & $\begin{array}{l}>10 \text { years } \\
\text { of age }\end{array}$ & $6.7 \%$ & N/A \\
\hline $\begin{array}{l}\text { MA Sayeed et al. } \\
, 1995\end{array}$ & 1005 & $\begin{array}{l}\text { Cross-sectional } \\
\text { survey }\end{array}$ & $\begin{array}{l}\mathrm{SBP}=>140 \mathrm{~mm} \text { of } \mathrm{hg} \\
\mathrm{DBP}=>90 \mathrm{~mm} \text { of } \mathrm{hg}\end{array}$ & $\begin{array}{l}>15 \text { years } \\
\text { of age }\end{array}$ & $\begin{array}{l}\text { Prevalence } \\
\text { according to } \\
\text { SBP }=10 \% \\
\text { DBP }=9 \%\end{array}$ & $\begin{array}{l}\text { Age: } \mathrm{SBP}>50 \text { years } \\
(\mathrm{p}<0.001) \\
\mathrm{DBP}>50 \text { years }(\mathrm{p}< \\
0.001) \\
\mathrm{BMI}=>23.1 \\
\mathrm{SBP}=(\text { OR } 1.84) \\
\mathrm{DBP}=(\text { OR } 2.30)\end{array}$ \\
\hline $\begin{array}{l}\text { Rahim et al, } \\
2008\end{array}$ & 532 & $\begin{array}{l}\text { Cross-sectional } \\
\text { survey }\end{array}$ & $\begin{array}{l}\mathrm{SBP}=>140 \mathrm{~mm} \text { of } \mathrm{hg} \\
\mathrm{DBP}=>90 \mathrm{~mm} \text { of } \mathrm{hg}\end{array}$ & $>20-70$ & $\begin{array}{l}30.64 \% \\
31.53 \% \\
\text { (Male) } \\
29.36 \% \\
\text { (Female) }\end{array}$ & $\begin{array}{l}\text { Family history } \\
\text { Physical activity, } \\
\text { Smoking, Obesity }\end{array}$ \\
\hline Khan et al ,2009 & 393 & $\begin{array}{l}\text { Cross-sectional } \\
\text { survey }\end{array}$ & $\begin{array}{l}\mathrm{SBP}=>140 \mathrm{~mm} \text { of } \mathrm{hg} \\
\mathrm{DBP}=>90 \mathrm{~mm} \text { of } \mathrm{hg}\end{array}$ & $18-60$ & $\begin{array}{l}22.13 \% \\
\text { (Female) }\end{array}$ & $\begin{array}{l}\text { Betel leaves, Jarda } \\
\text { Anxiety } \\
\text { Extra salt } \\
\text { consumption }\end{array}$ \\
\hline \multicolumn{7}{|c|}{ Both Urban and Rural Community } \\
\hline HTN study group,2001 & 1203 & $\begin{array}{l}\text { Cross-sectional } \\
\text { survey }\end{array}$ & $\begin{array}{l}\mathrm{SBP}=>140 \mathrm{~mm} \text { of } \mathrm{hg} \\
\mathrm{DBP}=>90 \mathrm{~mm} \text { of } \mathrm{hg}\end{array}$ & $>60$ years & $\begin{array}{l}65 \% \\
\text { Male }=333 \\
\text { Female }=444\end{array}$ & $\begin{array}{l}\text { Sedentary life style } \\
\text { Higher BMI, } \\
\text { Diabetes Mellitus }\end{array}$ \\
\hline
\end{tabular}

an urban area. Since then the prevalence of HTN has been shown to be scaled up to $14 \%$ in one study and also to be $27.6 \%$ in another study by the same year of 2005 conducted on the urban affluent community of Dhaka city. Again, the prevalence was found to be $3.1 \%$ in a study carried out at the outdoor of the Dhaka medical college. And, a multi country study included only elderly participants done on both India and Bangladesh reported the prevalence as high as $65 \%$. This study was done in both urban and rural areas. The prevalence was seen to be around $6.7 \%$ among the adults of a rural population which was done in 1983 . And then the prevalence tends to rise up gradually up to $9.5 \%$ in 1995 and $30.64 \%$ in 2008 among the rural participants of Bangladesh. 
Another study focused on only rural female explored the prevalence to be $22.13 \%$ by 2009 .

\section{Trend of hypertension:}

The prevalence of HTN in both urban and rural area varied from year to year. According to data from the table I, it seems that prevalence of HTN in urban and rural area ranges from $2.5 \%$ to $22.03 \%$. Analysis of exponential trend reveals an increases in HTN among the urban and rural population at a rate of 0.04 per year $(\mathrm{R}=0.33)$ (Fig 2 ), where most of the studies age groups were above twenty years. Hence, the time trend of Bangladesh indicates that HTN prevalence is rising with the years.

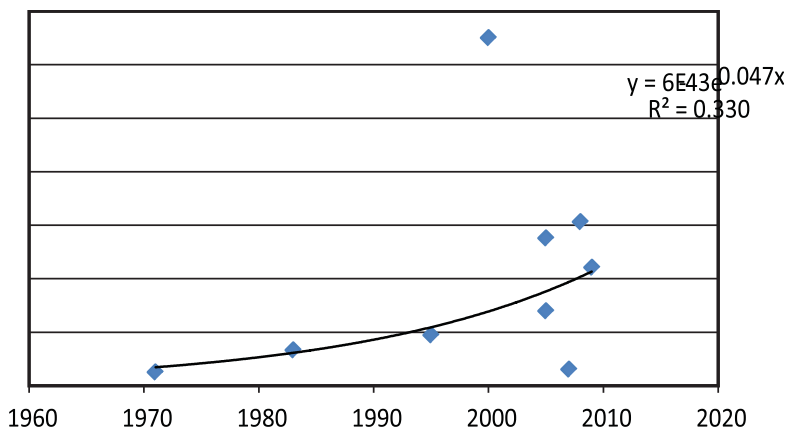

Fig.-2 : Trend of HTN in Bangladesh.

\section{Risk factors of hypertension:}

Most of the studies (7) discussed about the associated risk factors of HTN. Commonly BMI, tobacco smoking, extra salt intake, family history, and sedentary life style have found to be related with raised blood pressure among the participants. Two of the studies also showed a positive relationship of the age with HTN while one of the studies was only concerned with the elderly participants.

\section{Discussion:}

Due to lack of potential epidemiological studies at which level the risk of cardiovascular event increases is still not appropriately known in Bangladesh. And the mean prevalence seems to be lower in developing countries compare to the developed ones. Hence, the cut off BP value for having any of the cardiovascular events could consider being also lower in these countries. Likewise in this review, because of the absence of relevant literatures, most of the studies accepted
$\mathrm{SBP}>140 \mathrm{mmHg}$ or $\mathrm{DBP}>90 \mathrm{mmHg}$ criteria, one study used JNC VII criteria and one study used only diastolic $>90 \mathrm{mmHg}$ as the cut off level for the diagnosis of HTN in Bangladesh.

To estimate the prevalence of HTN both urban and rural areas of Bangladesh had been surveyed. And yet the precise prevalence of HTN remains unspecified. Besides, epidemiological studies on HTN are really scarce or data regarding that are not easily available. In this review as well, the prevalence was found to vary considerably across the studies. However, prediction of the trends and comparison among the studies are being difficult due to absence of the homogeneous definition and reference standards.

The earliest reported HTN prevalence was 2.58\% in both of the genders in an urban mixed community. Afterwards, two recent studies on 2005 demonstrated that the prevalence shot up to $14 \%$ and $27.6 \%$ respectively among the urban affluent communities. These findings were in concordance with the other studies conducted in the neighboring affluent north Indian and urban population of the Karachi, Pakistan where prevalence's were $32.2 \%$ and $38.5 \%$ respectively. ${ }^{16,17}$ Finally, the prevalence was mere $3.11 \%$ in a study done at the outdoor of the Dhaka Medical College showed. But the population size was too big $(17,792$ respondents and too generalized, all the Dhaka Medical College outdoor patients). Therefore, this may not hold at par with other studies.

Opposing the general belief, HTN is also being prevalent among the rural participants gradually. Using only the diastolic criteria the rural prevalence was found to be $6.7 \%$ in $1983 ; 10.5 \%$ had high systolic blood pressure and 9\% high diastolic blood pressure in 1995. In 2008, it was seen to be as high as $30.64 \%$ in one of the Bangladeshi village population. This finding was kindly in line with another study conducted in the rural population of Patna and Bihar. ${ }^{18}$ On the other hand, a study done among rural women of revealed the prevalence was $22.13 \%$. This result was consistent with another study conducted among Nepali adult rural women and where the prevalence was $17.7 \% .{ }^{19}$

Irrespective of the study design, most of the studies reviewed the risk factors. Though the specific 
causes of HTN is not properly established yet in this review higher BMI, sedentary lifestyle, tobacco smoking and extra salt taking were found to be the common risk factors on the urban community. These findings are comparable with the studies from other developing countries which recognized the similar risk factors. ${ }^{16,17}$ Similarly, extra salt consumption, betel nut chewing, anxiety high fatty meal, was found to be positively associated with HTN in the rural areas as well. And studies from rural Nepal and India found to be in accordance with this result. In contrast, two of the studies found occupation of the respondents insignificant. Family size, sex, education level, and urban or rural living also seem to have no imminent impact on developing hyper tension.

\section{Limitations:}

Although an extensive study has been done within the scope, but more could have been done if there were more available relevant literatures. Besides, only the literatures/ secondary resources written in English have been referred. Given the topic of the study it can be safely assumed that there are many other studies conducted in other languages as well. Since, only nine specific studies have been referred this can't depict the holistic scenario. However, due to the fact that the studies were heterogeneous in terms of the reference standards and study site, the overall understanding was substantiated. Moreover, information on certain groups, such as tribal or ethnic minorities, is missing. And, there might have been other unpublished studies that are not available online which could not be revealed. Hence, this review article does not provide representative data of Bangladesh. Nevertheless, the findings of this review provide useful insights for future research needs in this area.

\section{Conclusion:}

With the increasing process of urbanization and industrialization, along with the other noncommunicable diseases, HTN can be an alarming problem for the developing countries including Bangladesh. And HTN places an excessive financial burden on population and health systems, consuming scarce resources. But Bangladesh still mainly keeps focusing on communicable disease and reproductive health issues other than NCDS. Hence, it's very important to estimate the magnitude and associated risk factors in order to tackle this escalating problem. This review article can be suggestive to precede studies in large scale that would be representative of Bangladesh. And the findings also emphasize the need of a sustainable strategy including population based awareness and other preventive approaches for the management in developing countries. Therefore, combined approaches for screening of high blood pressure, monitoring of risk factors, improved research and surveillance or evaluation of the health system interventions must be given high priorities.

\section{Conflict of Interest - None.}

\section{References:}

1. Leowski J, Krishnan A. Capacity to control noncommunicable diseases in the countries of SouthEast Asia. Health Policy 2009; 92(1): 43-48.

2. Tunstall-Pedoe H. Preventing Chronic Diseases. A Vital Investment: WHO Global Report. Geneva: World Health Organization, 2005. Int J Epidemiol 2006; 35(4): 11071107.

3. El-Saharty S, Ahsan KZ, Koehlmoos TLP, Engelgau MM. Tackling Noncommunicable Diseases in Bangladesh: Now is the Time. Washington DC: World Bank Publications, 2013:1-3.

4. Director General of Health Service, MOHFW. Strategic plan for surveillance and prevention of Noncommunicable Disease in Bangladesh 2007-2011. 2007:1-46.

5. Krishnan A, Garg R, Kahandaliyanage A. Hypertension in the South East Asia region. Regional Health Forum: WHO South East Asia Region 2013. 17(1): 7-14.

6. Alwan A. Global status report on noncommunicable diseases 2010. World Health Organization. 2011: 9-31.

7. Ullaht W. Hypertension in a mixed community. BMRC Bulletin 1976. 2: 95-99.

8. Alamgir AKM, et al. Hypertension Prevalence and Related Factors in an Urban Affluent Community in Bangladesh. Bangladesh Journal of Medical Science 2005. 11: 22-30.

9. Alamgir AKM, Akhter SFU, Abedin E, Akhter S, Hossain N, Islam MS. Pattern of Blood Pressure Profile and Treatment Seeking Behavior in a Selected Urban Community in Bangladesh. J Dhaka Natl Med Coll Hosp 2005; 10:7-14

10. Kabir A, Barman TK, Yousuf NA, Fatima N, Banik J. Prevalence of Hypertension among the Patients who attend medicine outdoor of Dhaka Medical College Hospital. Journal of Medicine 2007. 8(2): 49-52.

11. Islam N, Khan M, Latif ZA. Hypertension in the rural population of Bangladesh-a preliminary survey. Bangladesh Medical Research Council bulletin 1983. 9(1): 11-14. 
12. Sayeed MA, Khan AR, Banu A, Hussain MZ, Ali SM. Blood pressure and glycemic status in relation to body mass index in a rural population of Bangladesh. Bangladesh Medical Research Council bulletin 1994; 20(2): 27-35.

13. Rahim MA, Rahman MM, Rahman M, Chowdhury J, Islam F. The prevalence rate of hypertension in rural population of Bangladesh. Journal of Dhaka National Medical College \& Hospital 2012; 18(1): 12-17.

14. Khan NR, et al. Prevalence of hypertension and associated risk factors among adult rural women. Journal of Dhaka Medical College 2008; 20(2): 153158.

15. Hypertension Study Group. Prevalence, awareness, treatment and control of hypertension among the elderly in Bangladesh and India: a multicentre study. Bulletin of the World health Organization 2001. 79(6): 490.
16. Yadav S, Boddula R, Genitta G, Bhatia V, Bansal B, Kongara $\mathrm{S}$ et al. Prevalence \& risk factors of prehypertension \& hypertension in an affluent north Indian population. Indian J Med Res 2008. 128(6): 712-720.

17. Dodani S, Mistry R, Farooqi M, Khwaja A, Qureshi R, Kazmi K. Prevalence and awareness of risk factors and behaviours of coronary heart disease in an urban population of Karachi, the largest city of Pakistan: a community survey. Journal of Public Health 2004. 26(3): p. 245-249.

18. Singh R, Sinha RK, Mani C, Singh R, Pal R. Burden and vulnerability of hypertension in a rural population of Patna, Bihar, India. South East Asia Journal of Public Health 2011 ; 1(1): 53-58.

19. Khan RJ, Stewart CP, Christian P, Schulze KJ, Wu L, LeClerq SC et al. A cross-sectional study of the prevalence and risk factors for hypertension in rural Nepali women. BMC public health 2013 ;13(1):55. 